\title{
Processo de envelhecimento sob a ótica de idosos participantes de um centro de convivência
}

\author{
Aging process under the perspective of elderly participants in a \\ center of coexistence
}

\author{
Elen Ferraz Teston'; Rubia Maiara Silva Marcon²; Sonia Silva Marcon³
}

\section{Resumo}

O processo de envelhecimento requer novos investimentos, tanto políticos quanto sociais, afim de que o idoso vivencie esta fase de forma natural e saudável. Diante disso, o presente estudo tem como objetivo conhecer a percepção de idosos sobre a sua participação nas atividades promovidas por um centro de convivência. Trata-se de um estudo exploratório de abordagem qualitativa, realizado em Maringá-PR, junto a 13 idosas. Os dados foram coletados em outubro de 2011 no próprio centro de convivência, mediante entrevistas semiestruturadas e após, submetidos à análise de conteúdo. Os resultados apontam os fatores valorizados pelas idosas quanto a vivência proporcionada pelas atividades, como por exemplo, o lazer, a ocupação e a melhora do estado de ânimo, o cuidado com a saúde, a busca por hábitos saudáveis de vida e a alfabetização. Além disso, evidenciaram-se indicadores de satisfação relacionados ao centro de convivência, como a assiduidade dos idosos nas atividades e a indicação a outros idosos. Diante disso, reconhece-se a vivência positiva por parte dos idosos, quanto à participação em atividades promovidas pelo centro de convivência e reforça-se a necessidade de os profissionais de saúde indicarem a participação nestas atividades como forma de contribuir com a promoção do envelhecimento saudável.

Palavras-Chaves: Envelhecimento. Comportamentos saudáveis. Promoção da saúde.

\begin{abstract}
The aging process requires new political and social investments, so that the elderly can experience this phase as natural and healthy. Therefore, this study aims to understand the perception of the elderly on their participation in activities sponsored by a community center. This is an exploratory qualitative study conducted in Maringá - PR , along with 13 elderly subjects. Data were collected in October 2011 at the center of coexistence through semistructured interviews and further subjected to content analysis . The results indicated the main factors valued by the elderly as the experience afforded by activities, such as leisure, occupation and improvement of mood, health care and pursuit of healthy lifestyles and literacy. Moreover, indicators of satisfaction related to the Center of coexistence became evident, as the attendance to the activities and the possibility to alert other seniors to participate. Therefore, we recognize the positive experience proportionated to the elderly in participating in the activities sponsored by the Center for Living and reinforces the need for health professionals to indicate these activities as a way of contributing to the promotion of healthy aging .
\end{abstract}

Keywords : Aging. Healthy behaviors. Health promotion.

\footnotetext{
${ }^{1}$ Doutoranda em Enfermagem na Universidade Estadual de Maringá (UEM) - PR. Email: elen-1208@hotmail.com

${ }^{2}$ Acadêmica do curso de Arquitetura e Urbanismo, Unicesumar, Maringá-PR

${ }^{3}$ Doutora em filosofia da Enfermagem. Coordenadora do Programa de Pós-Graduação em Enfermagem da UEM e do NEPAAF - PR
} 


\section{Introdução}

Torna-se cada vez mais relevante estudar a complexidade do processo de envelhecimento bem como os fatores que contribuem para a promoção do envelhecimento saudável, visto constituir um fenômeno mundial (PEREIRA, et al, 2011). A luta pela cidadania do idoso no Brasil tem se constituído em objeto de discussões e encaminhamentos de inúmeros grupos, porém, muito ainda está por fazer. Em 2006, a saúde do idoso surge como uma das seis prioridades pactuadas no "Pacto pela Saúde" que possuía o objetivo de estabelecer novos compromissos e responsabilidades em nível federal, estadual e municipal, com ênfase nas necessidades de saúde da população (BRASIL, 2006). No mesmo ano, foi aprovada também a Política Nacional de Saúde da Pessoa Idosa regulamentada pela Lei 8.842/94, que tem como finalidade assegurar os direitos sociais do idoso, criando condições para promover sua autonomia, integração e participação efetiva na sociedade. Ela traz responsabilidades partilhadas pelo Estado, família, sociedade civil, ministério público, órgãos públicos e instituições sociais (BRASIL, 1994). Além disso, retoma o estabelecido na Constituição Federal ao afirmar que compete à família, à sociedade e ao Estado o dever de assegurar ao idoso todos os direitos de cidadania, garantindo sua participação na comunidade, defendendo sua dignidade, bem-estar e o direito à vida, afirmando que não deve sofrer discriminação de qualquer natureza, e que cabe ao mesmo ser o principal agente e o destinatário das transformações a serem efetivadas através desta política (BRASIL, 1994; CAMPOS, 2004).

Considerando o marco legal que resguarda os direitos da população idosa, surgiram iniciativas legislativas e administrativas - no âmbito nacional e internacional - de proteção à saúde, promoção social e amparo à velhice. $\mathrm{O}$ envelhecimento saudável e ativo constitui uma meta para o entendimento de que as políticas direcionadas ao idoso, devem ser, necessariamente, intersetoriais (ELAINE,2010).

A abordagem do envelhecimento ativo é baseada no reconhecimento dos direitos humanos das pessoas mais velhas e nos princípios de independência, participação, dignidade, assistência e auto-realização estabelecidos pela Organização das Nações Unidas. Esta abordagem apóia a responsabilidade dos mais velhos no exercício de sua participação nos processos políticos e nos outros aspectos da vida em comunidade como a melhoria da qualidade de vida desta população por meio do aumento de sua participação em atividades diversas como cursos de informática, de línguas, de artesanato, entre outros; da formação de laços de relacionamento. Acredita-se que, desta forma, evita-se transtornos de humor, promove-se a reinserção social, a preservação e manutenção da autonomia, independência e dignidade do idoso (KEINERT, 2009).

Neste contexto, o maior desafio na atenção à pessoa idosa é contribuir para que, apesar das progressivas limitações oriundas da idade que possam ocorrer, elas possam redescobrir possibilidades de viver sua própria vida com a máxima qualidade possível. Essa possibilidade aumenta à medida que a sociedade considera o contexto familiar e social e reconhece as potencialidades e o valor das pessoas idosas (KEINERT, 2009).

Considerando que o centro de convivência foi desenvolvido com o intuito de proporcionar qualidade de vida ao idoso de forma a colocar em ação os direitos desta população e reintegrar o idoso ao convívio social, como ação de promoção a saúde, faz-se necessário investigar como os idosos vivenciam esta proposta. Assim, definiu-se como objetivo deste estudo conhecer a percepção de idosos sobre a sua participação nas atividades promovidas por um centro de convivência. 


\section{Métodos}

Estudo exploratório de abordagem qualitativa, realizado em um centro de convivência, localizado no município de Maringá-PR. Este município está localizado na região noroeste do Estado, tem uma população de 357 mil e 12,2\% é constituído por idosos (IBGE,2010). Em 2006 teve início a política de incentivo à adoção de hábitos saudáveis com implantação das academias da terceira idade e hoje existem 47 instaladas em diversos bairros da cidade. Existem, ainda, 10 Abrigos de Longa Permanência, três Centros Dia, 31 Centros de Convivência e um Condomínio do Idoso. Os informantes do estudo foram 13 idosas que participam ativamente de pelo menos uma das atividades do Centro de Convivência Palmeiras há mais de 2 anos.

A coleta de dados foi realizada em outubro de 2011, por meio de entrevista semiestruturada seguindo um roteiro constituído de duas partes: a primeira com questões referentes á identificação do individuo e a segunda com questões abertas elaboradas pelos próprios autores com base no objetivo do estudo, relacionadas às mudanças ocorridas após começar a freqüentar o centro de convivência.

As entrevistas foram realizadas no próprio centro de convivência e, com o consentimento dos participantes, foram gravadas em equipamento digital do tipo MP4. Para análise dos dados, as entrevistas foram transcritas na íntegra e após, submetidas à análise de conteúdo modalidade temática, a qual trabalha com o significado das palavras. Foram seguidas as fases de pré-análise, exploração do material, tratamento dos resultados e interpretação. Na primeira fase ou pré-análise, foram realizadas leituras das falas, com vista a levantar os pontos relevantes para o objetivo do estudo. $\mathrm{Na}$ segunda fase, a de exploração do material, procedeuse à codificação dos dados, processo pelo qual os dados brutos são transformados sistematicamente e agregados em unidades. Na última etapa, a de tratamento dos resultados, foi realizada a categorização, que consiste na classificação dos elementos segundo suas semelhanças e por diferenciação, com o posterior reagrupamento em função de características comuns (BARDIN,2008).

O desenvolvimento do estudo ocorreu em conformidade com o preconizado pela Resolução $n^{\circ}$ 196/96 do Conselho Nacional de Saúde, e foi aprovado pelo Comitê Permanente de Ética em pesquisa envolvendo Seres Humanos da Universidade Estadual de Maringá (Parecer $\mathrm{n}^{\circ}$. n619 2011). Todos os participantes assinaram o Termo de Consentimento Livre e Esclarecido, dando anuência à sua participação, em duas vias. Para a diferenciação dos sujeitos e preservação de sua identidade foram utilizados os seguintes códigos: letra $E$, referenciando a fala da entrevistada seguida pelo número da entrevista e por fim a idade.

\section{Resultados}

Participaram da pesquisa 13 mulheres com idade média de 67 anos. O tempo de freqüência no centro de convivência variou de 6 meses a 2 anos. A maior parte delas residem apenas com o esposo e possuem baixa escolaridade. Todas contribuem com a renda familiar, sendo nove aposentadas e quatro que recebem benefício. Todas as idosas apresentam pelo menos um problema de saúde referido sendo que a hipertensão arterial sistêmica (HAS) acomete a maioria (nove) delas (quadro 1). 
Quadro 1 - Caracterização das idosas do Centro de Convivência Palmeiras- Maringá, PR - 2011.

\begin{tabular}{cccccc}
\cline { 1 - 2 } Identificação & Idade\# & Moradia & Escolaridade & Renda* & Problemas de saúde \\
\hline E 1 & 65 & Acompanhado & Analfabetolaté a 3 serie fundamental & 3 & HAS \\
E 2 & 77 & Acompanhado & Analfabetolaté a 3 serie fundamental & 3 & DM; HAS; Osteoporose \\
E 3 & 73 & Acompanhado & Analfabetolaté a 3 serie fundamental & 3 & Gastrite; Nervosismo \\
E 4 & 60 & Acompanhado & Fundamental completo & 1 & HAS; Depressão; DM \\
E 5 & 63 & Acompanhado & 4 serie fundamental & 1 & Osteoporose; Osteopenia; HAS \\
E 6 & 68 & Acompanhado & 4 serie fundamental & 2 & HAS; DM \\
E 7 & 71 & Sozinho & Analfabetolaté a 3 serie fundamental & 1 & HAS \\
E 8 & 63 & Acompanhado & 4 série fundamental & 2 & Alergia Respiratória \\
E 9 & 69 & Sozinho & Analfabetolaté a 3 serie fundamental & 2 & Artrite; HAS; Dislipidemia; Tireoidite \\
E 10 & 73 & Sozinho & Analfabetolaté a 3 serie fundamental & 2 & HAS; Bronquite \\
E 11 & 69 & Acompanhado & Analfabetolaté a 3 serie fundamental & 3 & HAS; Dislipidemia \\
E 12 & 66 & Sozinho & Analfabetolaté a 3 serie fundamental & 1 & Dislipidemia; Cardiopatia; \\
E 13 & 63 & Acompanhado & Analfabetolaté a 3 serie fundamental & 2 & Gastrite crônica
\end{tabular}

\# Idade em anos. *Renda em salários mínimos. HAS: hipertensão arterial sistêmica; DM: diabetes mellitus

Fonte: dados coletados pelos próprios autores.

A análise temática dos dados permitiu a identificação de duas categorias que serão descritas a seguir.

\section{Vivenciando oportunidades antes negadas}

Dentre os benefícios promovidos pelo envolvimento em atividades do centro de convivência, destaca-se:

Lazer, oriundo das diferentes atividades disponíveis.

Antes eu não saia, ficava só em casa. Hoje eu saio bastante, porque aqui tem bastante passeio. E7, 71 anos.

Primeiro eu entrei aqui no bordado, depois comecei na ginástica também, coisas que antes eu não tinha tempo para fazer. É divertido, a gente conhece muita gente, sempre tem lugar para ir, porque eles mandam ônibus pra gente passear [...] Um pouquinho que você conversa já tira a mente da rotina. E6,68 anos.

O bom daqui é que tem passeios, a gente acaba conhecendo outros lugares... Tem a ginástica também, festinhas e baile... coisas que a gente precisa para relaxar... E12, 66 anos.

\section{A ocupação e a melhora no estado de ânimo.}

Dentro de casa você só fica fazendo serviço e depois come e vai dormir. E aqui não. Você passa o dia que nem vê. E11, 69 anos.

[...] ocupa a cabeça né, conversa com gente diferente. $\mathrm{E} 13,63$ anos.

[...] eu acho que não é porque a gente tem a idade da gente que tem que ficar em casa esperando a morte, porque vim ela vem de qualquer jeito. Então tem que sair, conversar, se ocupar para conseguir ser feliz e tirar as coisas ruins da cabeça. E9, 69 anos.

[...] tá sendo bom para cabeça, às vezes eu to meio pra baixo ai encontro as amigas jogo bingo, faço ginástica, vamos passear e quando vejo já estou com outro animo... E8, 63 anos.

O reconhecimento da importância de se cuidar da saúde fisica e de adquirir hábitos saudáveis.

[...] Aqui a gente aprende de tudo um pouco... comer direitinho por exemplo, sempre tem a nutricionista que vem e explica bastante coisa. E4, 60 anos.

[...] eu tenho amigas que moram lá na minha rua que estão tudo travada, reclamando de dor, chorando, com depressão... Eu sempre chamo para vim para cá... Aqui a gente se cuida, se distrai, faz exercícios, conhece coisas diferentes que fazem bem para nós e para nossa saúde. Aqui não dá tempo para ficar 
lembrando e sofrendo por outras coisas. Chega a noite eu quero ver minha novela, mais nem consigo porque estou tão cansada que chego a dormir sentada. Então é assim, a gente se ocupa e isso é saudável, porque a gente esta cuidando da gente. E8, 63 anos.

[...] tinha ficado quase 20 dias no hospital, e o médico falou que eu precisava de exercícios... Então vim para o centro e comecei a fazer alongamento e a ginástica, a dor diminuiu bastante. E1, 65 anos.

Eu acho tão bom vir aqui, bom pra saúde da gente, saúde do corpo, saúde da mente, do coração e até de espírito. E9, 69 anos.

\section{Oportunidade de alfabetização.}

Estou aprendendo a estudar porque antes eu não tinha como. Primeiro eu morava no sítio e nem sei se tinha naquela época estudo e depois que casei tinha que cuidar da casa e dos filhos. Então a chance é agora. E isso é importante, por que quando eu ia no mercado precisava ficar perguntando o preço das coisas e a validade, porque não sabia ver sozinha. E2, 68 anos.

Eu gosto daqui porque eu comecei a estudar, já sei até assinar meu nome... Só não sei se vou passar de ano. E3, 73 anos.

Estou aprendendo um pouquinho, tem que estudar, porque antes eu não tive chance, e eu não sabia nem qual ônibus pegar porque não sabia ler nada... E5,71 anos.

Indicadores de satisfação com relação a participação de atividades no centro de convivência

A participação e o compromisso com as diferentes atividades envolvem fatores como a afinidade e desejo pessoal. Evidenciou-se dois indicadores de satisfação com relação a participação nas atividades promovidas pelo centro de convivência, sendo eles:

- $\quad$ A frequência nas atividades:

Não tem nada que eu não goste aqui.... Nunca senti vontade de faltar não. E1, 65 anos.

Faltei uma vez mais foi porque não tinha como vir, estava doente. E3, 73

[...] eu tenho medo de faltar e ter alguma coisa e eu perder a oportunidade de ir para algum lugar. E4, 60 anos.

[...] Quando é tempo das férias eu acho tão ruim. Eu sinto falta de estar com os amigos que eu arrumei, de sair, dar risada. E6, 68 anos.
- A recomendação do centro de convivência para outras pessoas:

Já recomendei para as amigas lá da rua. Sempre falo que aqui é muito bom, ajuda a abrir a mente e distrai. E2, 68 anos.

Recomendo para as minhas amigas que não freqüentam pois faz muito bem participar. E3, 73

É bom para as pessoas não ficar só dentro de casa, de baixo astral. E eu acredito que aqui as pessoas se sentem mais feliz, então eu vivo chamando minhas amigas. E10, 70 anos.

\section{Discussão}

O envelhecimento ativo é a melhor forma de prolongar a vida com qualidade. Além disso, ter atividades de lazer contribuem para a satisfação do individuo de uma forma geral (SILVA; BACELAR,2011). Observa-se através das falas do E6 e E7 que a participação em atividades no centro de convivência representa uma oportunidade de acesso a atividades e passeios até então não vivenciados, o que confere novo sentido à vida e permite ao idoso reconhecer aspectos positivos presente no processo de envelhecimento. Estudo realizado junto a 2.143 idosos residentes na zuna urbana de Uberaba, $\mathrm{MG}$, Brasil, apontou que o envolvimento do idoso em atividades de lazer, de acordo com seus interesse e limitações, influencia positivamente na qualidade de vida (TAVARES; CÔRTES; DIAS, 2011).

Observa-se nos depoimentos do E9 e E11 os benefícios advindos da ocupação, o que é apontado como fator de proteção no combate a tristeza, sentimentos de solidão além de proporcionar sentimento de satisfação pessoal. Estes resultados corroboram os de estudo realizado no município de Cândido Godói - RS, cujo objetivo foi analisar a percepção que os idosos possuem acerca de sua inserção em grupos da terceira idade, o qual evidenciou que após o início da participação nas atividades destes grupos, ocorreram mudanças positivas na condição de vida, como por exemplo, a conquista de novas amizades e o despertar de sentimento de valorização pessoal através da ocupação (BOTH, 2011). 
Deveras, a ocupação do idoso está diretamente relacionada à manutenção da autonomia (BORGES; BENEDETTI; FARIAS 2011). Dessa forma, cabe aos profissionais da saúde o incentivo quanto à realização de diferentes atividades ao longo da vida para manutenção da saúde física, mental e espiritual. Os resultados do presente estudo também reforçam o que foi encontrado em um estudo realizado com o objetivo de verificar a associação entre o nível de atividade física habitual e a capacidade funcional percebida por idosas participantes de grupos de convivência (BORGES; BENEDETTI; FARIAS 2011), o qual apontou que estes grupos parecem estimular a prática regular de atividades físicas aliadas a outras atividades, influenciando positivamente nos níveis de atividade física habitual e também na capacidade funcional das idosas, fatores estes que interferem diretamente na qualidade de vida e na busca por um envelhecimento saudável.

Um aspecto importante a ser discutido é a necessidade e a importância da realização de atividades durante a vida até mesmo como fator de proteção ao desenvolvimento de doenças. Estudo que procurou conhecer o significado do lazer para a vida dos freqüentares do Centro de Atenção Integral a Saúde do Idoso (CAISI) em São Luís - MA, (SILVA; BACELAR, 2011) apontou que a manutenção de atividades de lazer e exercícios físicos auxiliam na redução do declínio cognitivo e previne, por conseguinte, o desenvolvimento de doenças.

O suporte social é um dos recursos mais significativos usados pelos idosos e envolve a percepção do suporte recebido, o senso de controle sobre as relações sociais e a perspectiva de trocas que incluem fatores afetivos, emocionais e materiais (PRATA; FUENTES; MERCADANTE, 2012). Portanto, antes de tudo faz-se necessário pensar a velhice de maneira ativa, descartando o conceito errôneo de associar o envelhecimento a um crescente colapso do organismo físico.
Nesse sentido, destaca-se também nas falas dos E1, E4, E8 e E9 o despertar para os cuidados necessários a saúde e a busca de hábitos saudáveis que são proporcionados pelas atividades, assim como pelo convívio social. Estudo realizado com idosos do Centro de Convivência do idoso e do Serviço Social do Comércio do município de Dourados - MS apontou que as atividades desenvolvidas no centro contribuem com a promoção da saúde, devido às informações que são fornecidas diariamente, além disso, contribuem com a manutenção dos cuidados por parte dos idosos, pois as atividades favorecem a alta estima e satisfação pessoal o que influencia na maneira com que cuidam de sua própria saúde (MILLER; FIETZ, 2011).

$\mathrm{O}$ analfabetismo entre idosos, ainda constitui uma realidade nos países em desenvolvimento (VIDMAR, et al, 2011). A partir do relato dos E2, E3 e E5, pode-se inferir a importância que a alfabetização representa na vida do idoso, e que o acesso a alfabetização constitui uma oportunidade não vivenciada anteriormente. Pesquisa realizada com idosos frequentadores de programas socioeducativos mantidos por instituição de ensino superior revelou o valor conferido à educação e ao reconhecimento do seu papel como recurso facilitador de processos de desenvolvimento. A educação é um direito e como tal deve ser garantido aos idosos como requisito inquestionável de QV (SILVA; BACELAR, 2011). Além disso, o maior grau de instrução facilitará ao idoso apreender mais informações relacionadas às suas próprias condições de vida e saúde.

Evidenciou-se nas falas de E1, E3, E4 e E6, por exemplo, um indicador de satisfação quanto ao envolvimento nas atividades do Centro de Convivência, representado pela assiduidade do idoso. Não sentir vontade de faltar constitui um importante indicativo de gostar do que se faz, e principalmente de ter descoberto nas atividades realizadas uma ocupação prazerosa. Os centros de convivência surgem como um espaço de promoção do convício social e do envelhecimento ativo e saudável. Diante 
disso, precisamos disseminar essa informação para que um número maior de idosos conheça as atividades oferecidas e se identifiquem com algumas delas.

Nesse sentido, identificou-se ainda, o indicador de satisfação que constitui na referência das atividades vivenciadas no centro de convivência a amigos, vizinhos e parentes. Ser convidado ou querer participar é uma das formas de acesso do idoso ao grupo e percebemos que, ao iniciar as atividades, estes indivíduos gostam e motivam-se e passam a freqüentar continuamente, e tem uma avaliação positiva dos resultados proporcionados pelo grupo para suas vidas (BARCELOS-FERREIRA, 2010).

\section{Conclusão}

Partindo-se dos resultados obtidos na investigação, os idosos que dela participaram, consideraram, de modo geral, positiva a participação em atividades promovidas pelo centro de convivência. Destaca-se, portanto os benefícios oferecidos por estas atividades como o lazer, a ocupação e melhora do estado de ânimo, o reconhecimento da importância de cuidar da saúde e adquirir hábitos saudáveis assim como a oportunidade de alfabetização. Contataram-se também dois indicadores de satisfação relacionados a estas atividades, a assiduidade nas atividades e a indicação das mesmas aos amigos e conhecidos.

Portanto, reconhecendo os benefícios proporcionados pelas atividades desenvolvidas no centro de convivência, evidenciadas pelos participantes do estudo, sugere-se a divulgação da existência destes centros bem como o incentivo, por parte dos profissionais de saúde, quanto a participação e envolvimento dos idosos nestas atividades.

Como limitação do estudo considera-se o fato de as informações terem sido obtidas junto a idosos participantes de apenas um dos centros de convivência do município, já que pode ser influenciada pelo próprio ambiente e profissionais envolvidos. Entretanto, parece razoável concluir, a partir da vivência destas idosas que participar de atividades que lhes proporcione prazer e estabelecer vínculos sociais contribui de maneira direta para o processo de envelhecimento saudável.

\section{Referências}

BARCELOS-FERREIRA, R. et al. Depressive morbidity and gender in community-dwelling Brazilian elderly: systematic review and metaanalysis. International Psychogeriatric., New York, v. 22, no. 5, p. 712-726, Aug. 2010.

BARDIN, L. Análise de conteúdo. Lisboa (PT): Edições 70; 2008.

BORGES, G.F.; BENEDETTI, T.R.B.; FARIAS S.F. Atividade física habitual e capacidade funcional percebida de idosas do sul do Brasil. Pensar a prática, v.14, n.1,1-11,2011.

BOTH, J.E., et al.Grupos de convivência:Uma Estratégia de Inserção do Idoso na Sociedade. Revista Contexto e saúde, v.10,n.20,p. 99598,2011.

BRASIL. Ministério da Saúde. Secretaria Executiva. Diretrizes operacionais dos pactos pela vida, em defesa do SUS e de Gestão. Brasília, DF, 2006.

BRASIL. Ministério da Saúde. Lei 8.842 de 4 de janeiro de 1994. Dispõe sobre a política nacional do idoso, cria o Conselho Nacional do Idoso e dá outras providências. Brasília, DF, 1994. Disponível em: <http://www.pge.sp.gov.br>. Acesso em: 19 ago. 2011.

CAMPOS, S. Política Nacional de Saúde do Idoso: geriatria/idoso. 2004. Disponível em: $<$ http://www.drashirleydecampos.com.br/ noticias/13887>. Acesso em: $1 \mathrm{dez} .2011$.

ELAINE, F., et al. Programa Boa Vida. Revista gestão Pública em Curitiba, v.1,n.3,p.75,2010. 
IBGE. Censo Demográfico 2010. 2010a. Disponível em: <http://www.censo2010.ibge.gov.br/>. Acesso em: 12 nov. 2011.

KEINERT, T.M.M.; ROSA, T.E.C. Direitos Humanos, envelhecimento ativo e saúde da pessoa idosa: marco legal e institucional. Boletim do Instituto de Saúde, São Paulo, v. 37, p 4-8, abr. 2009. Disponível em: http://periodicos.ses.sp.bvs. br/scielo.php? script $=$ sci_arttext $\&$ pid $=$ S 1518 $18122009000200002 \& \operatorname{lng}=\mathrm{pt}$

MILLER, N.; FIETZ, V.R. Educação em saúde e educação nutricional aos idosos o Centro de Convivência do idoso no município de Dourados. Periódico UEMS, v.1, n.3, p.7-13, 2011.

PEREIRA, R.J. et al. Influência de fatores sociossanitários na qualidade de vida dos idosos de um município do Sudeste do Brasil. Ciência \& Saude Coletiva, v.16, n.6, p. 2907-17, 2011.

PRATA, S.A.M.; FUENTES, S.; MERCADANTE, E.F. Reflexões sobre o autocuidado praticado na velhice. Revista Ciências em Saúde, v.2, n.1, p.110, 2012.

SILVA, L.R.M.S.; BACELAR, A.T.R.F.D. $O$ que pensam os idosos frequentadores do Centro de Atenção integral a Saúde do idoso (CAISI) em São Luís (MA) sobre o lazer. Revista Portal de Divulgação, v.65, n.1, p.21-5, 2011.

TAVARES, D.M.S.; CÔRTES, R.M.; DIAS, F.A. Qualidade de vida de idosos com diabetes mellitus. Ciência Cuidado e Saúde, v.10, n.2,p. 290-97, 2011.

VIDMAR, M.F., et al. Atividade física e qualidade de vida em idosos. Revista Saúde e Pesquisa, v.4, n.3, p. 417-24, 2011. 